Созаева Л.Т., Высокогорный геофизический институт, г. Нальчик, Россия

Шериева М.A., ljk_62@rambler.ru

Шунгаров И.Х. ryer16@yandex.ru

Шагин С.И

Российский университет дружбы народов, г. Москва, Россия e-mail: sozaev.islam@mail.ru

Кабардино-Балкарский государственный университет им.Х.М. Бербекова, г. Нальчик, Россия

\title{
ЗАГРЯЗНЕНИЕ АТМОСФЕРНОГО ВОЗДУХА ВЫБРОСАМИ АВТОЗАПРАВОЧНЫХ СТАНЦИЙ
}

Введение. Загрязнение атмосферного воздуха является одной из актуальных проблем современности. Загрязняющие вещества, попадая в организм человека, оказывают негативное влияние на работу внутренних органов, слизистых оболочек, иммунитета, вызывают рост онкологических заболеваний. В городах России главными источниками антропогенного загрязнения атмосферного воздуха являются промышленные предприятия, автотранспорт, нефтедобыча и нефтепереработка и т.д. В данной работе рассматривается загрязнение атмосферного воздуха выбросами нефтепродуктов от эксплуатации автозаправочных станций на примере городского Материалы и методы округа Нальчик (юг России).

исследований. Для расчета характеристик выбросов используются методические указания по определению выбросов загрязняющих веществ в атмосферу из резервуаров. Для оценки степени негативного воздействия выбросов проводятся расчеты по программе «Эколог-4.5», реализующей методы рассеивания выбросов загрязняющих веществ в атмоссрерном воздухе. Все эти методы и программа утверждены в установленном порядке.

Результаты исследований

и их обсуждение. Приведены максимально-разовые и годовые выбросы компонентов паров моторного топлива. Представлены результаты расчетов рассеивания загрязняющих веществ, в качестве примера приведена карта рассеивания одного из загрязняющих веществ. Обнаружено, что на границе жилой зоны нет превышения предельно-допустимой концентрации по всем веществам.

Выводы. олученные результаты показывают, что годовой выброс загрязняющих веществ даже по одной из 25 заправок городского округа Нальчик значительный. Поэтому необходимо провести работы по их уменьшению.

Ключевые слова: автозаправочная станция, максимальная приземная концентрация, углеводороды, загрязняющие вещества, рассеивание выбросов, предельно допустимая концентрация (ПДК). 
Lezhinka T. Sozaeva, Federal state budgetary institution «High-Mountain geophysical institute», Nalchik, Russian Federation ljk_62@rambler.ru,

Maryana A. Sherieva, ryer16@yandex.ru

Islam Kh. Shungarov Friendship University of Russia, Moscow, Russian Federation sozaev.islam@mail.ru

Islam Kh. Shungarov Friendship University of Russia, Moscow, Russian Federation sozaev.islam@mail.ru

\section{POLLUTION OF THE ATMOSPHERIC AIR BY PETROL STATION EMISSIONS}

Introduction.

Materials and methods

Air pollution is one of the urgent problems of our time. Pollutants entering the human body have a negative impact on the work of internal organs, mucous membranes, immunity, and cause the growth of cancer. In Russian cities, the main sources of anthropogenic air pollution are industrial enterprises, motor transport, oil production and oil-refining, etc. In this paper the pollution of atmospheric air emissions of oil products from the use of petrol stations on the example of the city district of Nalchik (South of Russia) is considered.

of research.

For calculation of the emission characteristics a methodological guidance for estimating pollutants' emissions into the atmosphere from reservoirs are used. To assess the degree of emissions' negative impact, there are carried out calculations under the program «Ecologist- 4.5 », which implements methods of dispersion of pollutants' emissions in the air. All these methods and the program are

Research results and their discussion. approved in accordance with the established procedure.

The maximum-single and annual emissions of motor fuel vapor components are given. Results of calculations of pollutants' dispersion are described, as an example the map of dispersion of one of pollutants is showed. It was found that at the border of the living zone there is no excess of the maximum permissible concentration for all substances.

Conclusions. The results show that the annual emission of pollutants even at one of the 25 petrol stations of the city district of Nalchik is significant. Therefore, it is necessary to do much work to reduce it.

Keywords. Petrol station, maximum ground concentration, hydrocarbons, pollutants, dispersion of emissions, maximum permissible concentration (MPC).

\section{Введение}

Выбросы загрязняющих веществ от промышленных предприятий и автотранспорта оказывают экологический ущерб, вызывая загрязнение почвы, воды, атмосферы, что ведет к значительному ухудшению здоровья, способствует снижению качества и сокращению жизни населения. В настоящее время основными загрязняющими веществами, выбрасываемыми в атмосферный воздух городов, наряду с пылью и оксидами азота, являются углеводороды. Источником их поступления в атмосферу является автотранспорт и автозаправочные станции. Значительная часть вредных веществ накапливается на территориях резервуарных парков и прилегающих территориях на высоте до двух-трех метров. Именно до этой высоты поднимаются токсичные вещества, которыми дышат люди. Отрицательное влияние автозаправочных станций на окружающую среду связано еще и с тем, что преиму- 
щественно они размещаются в населенных пунктах с высокой плотностью застройки и значительной концентрацией автотранспорта.

В данной работе рассматривается загрязнение атмосферного воздуха выбросами углеводородов от автозаправки «Сириус», расположенной в центральной густо населенной части городского округа Нальчика. В нем проживают 240 тыс. человек, плотность населения составляет 3578 чел./км². Исследования показали, что выбросы оксидов азота и углерода от теплоснабжающих предприятий города составили около 750 т/год [1-3], а выбросы углеводородов, согласно отчетам надзорных органов по КБР, от эксплуатации только автотранспорта равны 300 т/год.

Для оценки выбросов загрязняющих веществ от автозаправки была проведена инвентаризация источников выбросов. Негативное воздействие выбросов было оценено по результатам расчетов максимальных приземных концентрации загрязняющих веществ, создаваемых на границе жилой зоны.

\section{Материалы и методы исследований}

На основании инвентаризации выбросов для АЗС «Сириус» было обнаружено, что источниками выделения загрязняющих веществ в атмосферу являются резервуары для моторного топлива и топливораздаточные колонки. Выброс загрязняющих веществ осуществляется от дыхательных клапанов резервуаров при хранении и заполнении нефтепродуктами, от топливных баков автомобилей при их заправке, при проливах за счет стекания нефтепродуктов со стенок заправочных и сливных шлангов.

Характеристики выбросов рассчитываются по методическим указаниям по определению выбросов загрязняющих веществ в атмосферу из резервуаров [4]. Максимальный разовый выброс определяется только для операции закачки нефтепродукта в резервуары, т.к. одновременная закачка нефтепродукта в резервуары и баки автомобилей не осуществляется. При оценке максимальных разовых выбросов из резервуаров заправки в качестве исходных данных принимаются объем нефтепродуктов, сливаемых из автоцистерны в резервуар, и время слива. Максимальная концентрация паров нефтепродуктов в выбросах смеси при заполнении резервуаров выбирается из таблиц в зависимости от конструкции резервуара и климатической зоны расположения заправки [4].

При эксплуатации АЗС в атмосферный воздух выбрасываются пары нефтепродуктов, которые имеют следующий компонентный состав: сероводород, метан, углеводороды предельные $\mathrm{C}_{1}-\mathrm{C}_{5}$, углеводороды предельные $\mathrm{C}_{6}-\mathrm{C}_{10}$, углеводороды предельные $\mathrm{C}_{12}-\mathrm{C}_{19}$, амилены, бензол, ксилол, толуол и этилбензол.

Расчеты рассеивания выбросов загрязняющих веществ проводятся по утвержденным в установленном порядке методам [5, 6]. Эти методы реализованы в программе «Эколог-4,5», которая позволяет рассчитывать максимальные значения приземных разовых концентрации загрязняющих ве- 
ществ при неблагоприятных метеорологических условиях на контрольных территориях.

Критерий оценки степени загрязнения атмосферного воздуха определяется из соотношения:

$$
\mathrm{C}_{\mathrm{j}} / \Pi Д \mathrm{~K}_{\mathrm{j}} \leq 1,
$$

где $\mathrm{C}_{\mathrm{j}}-\quad$ максимальная приземная разовая концентрация $\mathrm{j}$-го загрязняющего вещества, создаваемая выбросом рассматриваемого объекта, [мг/м3)];

ПДК $\kappa_{\mathrm{j}}-\quad$ предельно допустимая конщентрация $\mathrm{j}$-го загрязняющего

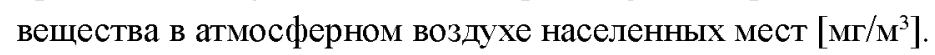

Метеорологические характеристики, определяющие условия рассеивания загрязняющих вешеств в атмосфере в районе расположения предприятия, устанавливаются по климатическим данным, опубликованным для всеобщего доступа в сети интернет.

Для города Нальчик средняя максимальная температура наружного воздуха наиболее жаркого месяца равна $+27,5^{\circ} \mathrm{C}$. Средняя температура наиболее холодного месяца составляет $-6,5^{\circ} \mathrm{C}$. Скорость ветра, повторяемость превышения которой по многолетним данным составляет 5\%, равна 6 м/с [7].

Для проведения детальных расчетов рассеивания выбросов в районе размещения заправки были заданы размеры и шаг расчетной сетки. Еще были выбраны четыре расчетные точки на границе санитарно-защитной зоны (С33) и одна точка на границе ближайшего жилого дома. Далее для каждого узла расчетной сетки, а также пяти расчетных точек определялись максимальные приземные концентрации загрязняющих веществ посредством перебора скоростей и направлений ветра. Скорости ветра перебирались от 0,5 до 6 м/сек. Направление ветра варьировалось по всему диапазону от 0 до 360 градусов с интервалом 1 градус.

\section{Результаты исследований и их обсуждение}

В таблице 1 приведены максимально-разовые (г/сек) и годовые (т/год) выбросы компонентов паров моторного топлива.

Из таблицы 1 видно, что в целом предприятие выбрасывает 3,188 тонн загрязняющих веществ в год.

Санитарно-защитная зона для автозаправочных станций 100 м. На расстоянии 20 м от данной заправки в пределах С33 располагается жилая зона. Поэтому необходима оценка негативное влияния выбросов не только на границе С 33, но, в первую очередь, на границе жилой зоны.

Результаты расчетов показали, что наиболее значимыми загрязнителями заправки «Сириус» являются: амилены, бензол, толуол и этилбензол. Остальные вешества, присутствующие в выбросах не являются источниками воздействия на среду обитания и здоровье человека, поскольку уровни со- 
Таблице 1

\begin{tabular}{|c|c|c|c|}
\hline $\begin{array}{l}\text { Загрязняющие } \\
\text { вещества }\end{array}$ & $\begin{array}{l}\text { пдк, } \\
\mathrm{mr} / \mathrm{M}^{3}\end{array}$ & $\begin{array}{l}\text { Максимально-разовый } \\
\text { выброс, г/сек }\end{array}$ & $\begin{array}{l}\text { Годовой выброс, } \\
\text { т/год }\end{array}$ \\
\hline Сероводород & 0,01 & 0,0000060 & 0,000069 \\
\hline Метан & 50 & 0,0368290 & 0,108052 \\
\hline $\begin{array}{l}\text { Углеводороды } \\
\text { предельные } \\
\mathrm{C}_{1}-\mathrm{C}_{5}\end{array}$ & 200 & 0,6991360 & 2,066880 \\
\hline $\begin{array}{l}\text { Углеводороды } \\
\text { предельные } \\
\mathrm{C}_{6}-\mathrm{C}_{10} \\
\end{array}$ & 50 & 0,1948440 & 0,761290 \\
\hline Амилены & 1,5 & 0,0194720 & 0,076100 \\
\hline Бензол & 0,3 & 0,0179140 & 0,070014 \\
\hline Ксилол & 0,2 & 0,0022560 & 0,008826 \\
\hline Толуол & 0,6 & 0,0169000 & 0,066054 \\
\hline Этилбензол & 0,02 & 0,0004620 & 0,001818 \\
\hline $\begin{array}{l}\text { Углеводороды } \\
\text { предельные } \\
\mathrm{C}_{12}-\mathrm{C}_{19}\end{array}$ & 1 & 0,0021210 & 0,024660 \\
\hline
\end{tabular}

здаваемого загрязнения на гранище жилой зоны не превышают 0,05 ПДК, а за пределами санитарно-защитной зоны не превышают 0,01 ПДК. На границе жилой зоны амилены создают концентрации 0,05 ПДК, бензол - 0,2 ПДК, толуол - 0,09 ПДК и этилбензол - 0,09 ПДК.

На рисунке 1 в качестве примера приведена карта рассеивания бензола, который создает на границе жилой зоны самое большое из вешеств загрязнение, равное 0,2 ПДК. На карте красной линией выделена граница санитарнозащитной зоны, зеленой - многоэтажное жилое здание, синим цветом - граница территории заправки.

\section{Выводы}

Таким образом, на границе жилой зоны ни одно загрязняющее вещество, выбрасываемое заправкой «Сириус» не превышает ПДК. Поэтому существующие выбросы можно принять в качестве нормативных. Однако, только одна среднестатистическая заправка выбрасывает в атмосферу более 3 т/год загрязняющих веществ. А таких заправок только в одном г. Нальчик около 25. Многие из них осушествляют свою деятельность без соблюдения норм пожарной безопасности и необходимых охранных и санитарно-защитных зон. 


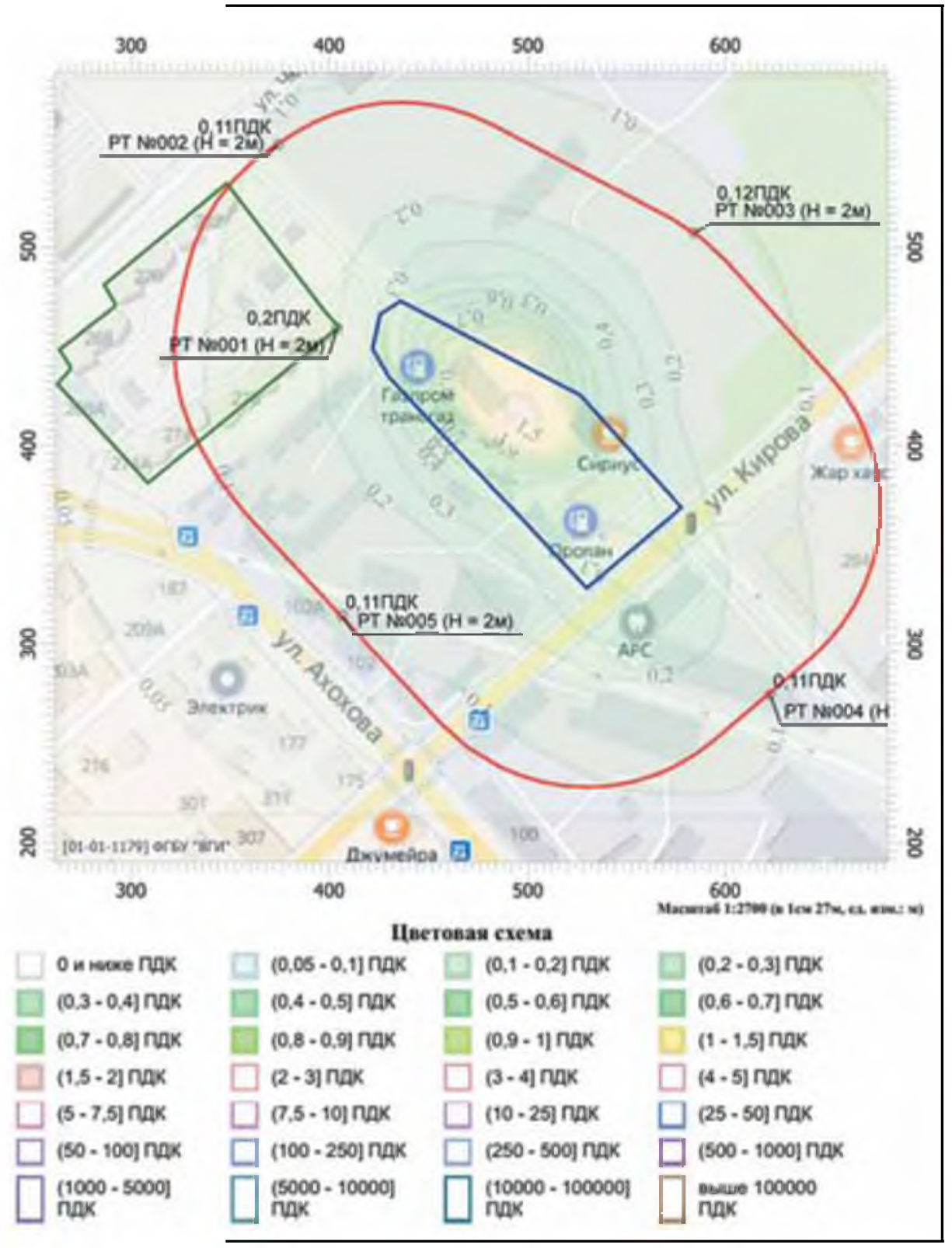

Рис. 1.

Карта рассеивания бензола в районе размещения заправки «Сириус».

Fig. 1. Map of benzene dispersion in the area of placement of petrol station «Sirius».

Поэтому, в обязательном порядке, необходимо проводить контрольные мероприятия по поддержанию в полной технической исправности технологическое оборудование, обеспечивая их герметичность. Надо проводить аналитический контроль выбросов загрязняющих веществ на резервуарах согласно периодичности контроля на источниках.

Для уменьшения выбросов от источников загрязнения автозаправок рекомендуется оборудовать топливные резервуары и топливораздаточные колонки эффективными системами улавливания паров моторного топлива. 


\section{Библиографический список}

1. Sozaeva L.T. Evaluation of Emission of Pollutants in the Atmosphere Produced by Heating Enterprises of Nalchik Town, Materials Science Forum. 2018. Vol. 931. P. 1047-1051.

2. Созаева Л.Т., Шунгаров И.Х., Хегай А.Г. Загрязнение атмосферного воздуха теплоснабжающими предприятиями города Нальчика. СПб.: Д'Арт, Труды ГГО. 2018. Вып. 590. С. 190-198.

3. Sozaeva L.T., Shungarov I. Kh. Air Pollution by Heat Supplying Enterprises of Nalchik, Advances in Engineering Research. 2019. Vol. 182. P. 285-289.

4. Методические указания по определению выбросов загрязняющих веществ в атмосферу из резервуаров. Новополоцк: МП «БЕЛИНЕКОМП», 1997.

5. Методическое пособие по расчету, нормированию и контролю выбросов загрязняющих веществ в атмосфферный воздух. СПб.: НИИ «Атмоссрера». 2012. $224 \mathrm{c}$

6. Приказ Министерства природных ресурсов и экологии Российской Федерации от 06.06.2017 № 273 «Об утверждении методов расчетов рассеивания выбросов вредных (загрязняющих) веществ в атмосорерном воздухе». Москва: Минюст РФ. 80 с.

7. https://www. meteoblue.com/ru/погода/historyclimate/climatemodelled/Haльчик_Россия_523523.

\section{References}

1. Sozaeva L.T. Evaluation of Emission of Pollutants in the Atmosphere Produced by Heating Enterprises of Nalchik Town, Materials Science Forum, Vol. 931. 2018. P. 1047-1051.

2. Sozaeva L.T., Shungarov I. Kh., Khegai A.G. The pollution of atmosphere air by heating enterprises of Nalchik town. St. Petersburg, LLC «D'art», Works of GGO. 2018. Vol. 590. P. $190-198$.

3. Sozaeva L.T., Shungarov I. Kh. Air Pollution by Heat Supplying Enterprises of Nalchik, Advances in Engineering Research, Vol. 182. 2019. P. 285-289.

4. Methodological guidelines for determining emissions of pollutants into the atmosphere from tanks. Novopolotsk, 1997. Novopolotsk: «BELINECOMP».

5. Methodological guidelines manual on measuring, rating and controlling emissions of pollutants in the atmospheric air, the Scientific Institute Atmosphera, Saint Petersburg. 2012.

6. About approval of methods of measuring dispersion of emission of pollutants in the atmospheric air. Order of the Ministry of natural resources and ecology of the Russian Federation from 6 June 2017, 273, the Ministry of Justice of the Russian Federation, Moscow, 2017.

7. https://www. meteoblue.com/ru/погода/historyclimate/climatemodelled/ Нальчик_Россия_523523.

Поступило в редакцию 19.11.2019, принята к публикации 02.12.2019

\section{Сведения об авторах}

Созаева Лежинка Танашевна - кандидат физико-математических наук, старший научный сотрудник, ФГБУ «Высокогорный геофизический институт».

Scopus ID 57204527832. 
E-mail: ljk_62@rambler.ru. Телефон: +7 (928) 7232008.

Шериева Марьяна Азреталиевна - младший научный сотрудник, ФГБУ «Высокогорный геофизический институт».

E-mail: ryer16@yandex.ru. Телесрон: +7 (928) 0804585

Шунгаров Ислам Хасанович - студент факультета физико-математических и естественных наук, Российский университет дружбы народов. E-mail: sozaev.islam@mail.ru. Телефон: 8(996) 916-25-29.

Шагин Сергей Иванович - начальник управления научно-исследовательской деятельностью, ФГБОУ ВО «Кабардино-Балкарский государственный университет им. Х.М. Бербекова». Адрес: РФ, Кабардино-Балкарская Республика, г. Нальчик, ул. Чернышевского, 173. Тел. 8(909) 487-77-22.

\section{About the authors}

Sozaeva Lezhinka Tanashevna - candidate of physical and mathematical Sciences, senior research associate of department of physics of clouds of Federal state budgetary institution «High-Mountain Geophysical Institute». Scopus ID 57204527832.

E-mail: ljk_62@rambler.ru. Phone: +7 (928) 7232008.

Sherieva Maryana Azretalievna - junior research associate, Federal state budgetary institution «High-Mountain Geophysical Institute».

E-mail: ryer16@yandex.ru. Phone: +7 (928) 0804585.

Shungarov Islam Khasanovich - student of Faculty of physics and mathematics and natural Sciences, Peoples' Friendship University of Russia. E-mail: sozaev.islam@mail.ru. Phone: 8(996) 9162529.

Shagin Sergey Ivanovich - head of research activities, Federal state budgetary educational institution of higher education «Kabardino-Balkarian state university named after H.M. Berbekov»). Address: Russia, Kabardino-Balkar Republic, Nalchik, Chernyshevskogo, 173 8(909) 487-77-22.

$\prod$

Издательство Северо-Кавказского фредерального университета. г. Ставрополь, ул. Пушкина, 1.

Корректор - М.И. Толмачев.

Компьютерная верска - О.Г. Полевич.

Подписано в печать 25.12.2019 г. Выход в свет 29.12.2019 г. Формат $70 \times 108$ 1/16. Гарнитура Times New Roman. Бумага офрсетная. Усл. печ. л. 15,5. Тираж 1000 экз. Цена 534 руб.

Отпечатано в Издательско-полиграфическом комплексе ФГАОУ ВО «Северо-Кавказский федеральный университет». 355029, г. Ставрополь, пр-т Кулакова, 2. 